ఠ

\title{
Variations in the sleep-wake cycle from childhood to adulthood: chronobiological perspectives
}

\author{
This article was published in the following Dove Press journal: \\ ChronoPhysiology and Therapy \\ 21 July 2015 \\ Number of times this article has been viewed
}

\section{Joanne S Carpenter \\ Rébecca Robillard \\ lan B Hickie}

Clinical Research Unit, Brain and Mind Research Institute, University of Sydney, Camperdown, NSW, Australia

\begin{abstract}
Changes in the sleep-wake cycle across development from childhood to adulthood, typically involve a steady shortening of the sleep period and a delay of sleep phase, with a period of more rapid change across adolescence. Accompanying these changes is the maturation of neuroendocrine rhythms such as melatonin, cortisol, and pubertal hormones. These endogenous rhythms are closely associated with behavioral changes in rest and activity rhythms, although environmental factors such as light exposure and academic and social demands likely play an interactive role. Other behavioral aspects, such as physical activity and eating behaviors, are also associated with changes in sleep-wake rhythms, and may be mediational factors in the development of physical illnesses. The sleep-wake cycle and related factors are implicated in the development of mental illnesses. There are several potential avenues of future research that may be valuable in terms of improving interventions and treatments for both mental and physical illnesses.
\end{abstract}

Keywords: circadian rhythm, developmental, adolescence, youth

\section{Introduction}

The human 24-hour sleep-wake cycle and underlying biological rhythms undergo several significant changes across development from childhood to adulthood. Adolescence in particular is characterized by substantial changes in the circadian pattern of activity and rest, which occur alongside pubertal maturation and neurodevelopment, including maturation of the neuroendocrine system. Changes in the sleep-wake cycle are also associated with lifestyle and environmental factors such as diet, exercise, and school schedules. Many of these changes take place in systems implicated in the development of mental and physical illnesses and as such it is important to consider sleep-wake and circadian rhythms as potential contributing factors to deviations from healthy development. This review aims to present an overview of the current literature on sleep-wake and circadian changes from childhood to adulthood, focusing on chronobiological aspects of these changes and associated roles in the development of illness.

\section{Changes in the timing of sleep and activity}

A consolidated sleep-wake pattern is generally established during the first 6 months of life, with the majority of waking activity occurring during the day and one main nocturnal sleep episode. ${ }^{1}$ Across infancy and childhood, this pattern continues to consolidate with a decrease in the frequency and duration of daytime naps. ${ }^{2,3}$ Mean habitual sleep duration also decreases steadily across this period (from 12.8 hours in 
infants to 11.9 hours in $2-5$ years old $),{ }^{4}$ and continues to do so throughout childhood (9.2 hours in 6-12 years old), ${ }^{4}$ the adolescent period ( 8.1 hours in 16 years old), ${ }^{2,5}$ and into adulthood ( 7.5 hours in 24 years old). ${ }^{6}$

The shortening of sleep duration across childhood and adolescence is accompanied by a delay in the phase of the sleep-wake cycle, particularly characterized by progressively later bedtimes., ${ }^{2,7}$ This delay of sleep onset becomes more pronounced in adolescence, with reports of 5-7 minutes delay per year from 7 to 9 years old, and 10-17 minutes delay from 9 to 12 years old. ${ }^{3}$ Wake-up times follow a slightly different pattern, remaining relatively stable across childhood, and beginning to occur later in adolescence, most prominently on weekends. ${ }^{7}$ The adolescent delay in the sleep-wake cycle is one of the most widely reported changes in sleep habits, with consistent reports across a variety of different cultures around the globe. ${ }^{5}$ Typical changes in sleep-wake timing from childhood to adulthood are illustrated in Figure 1.

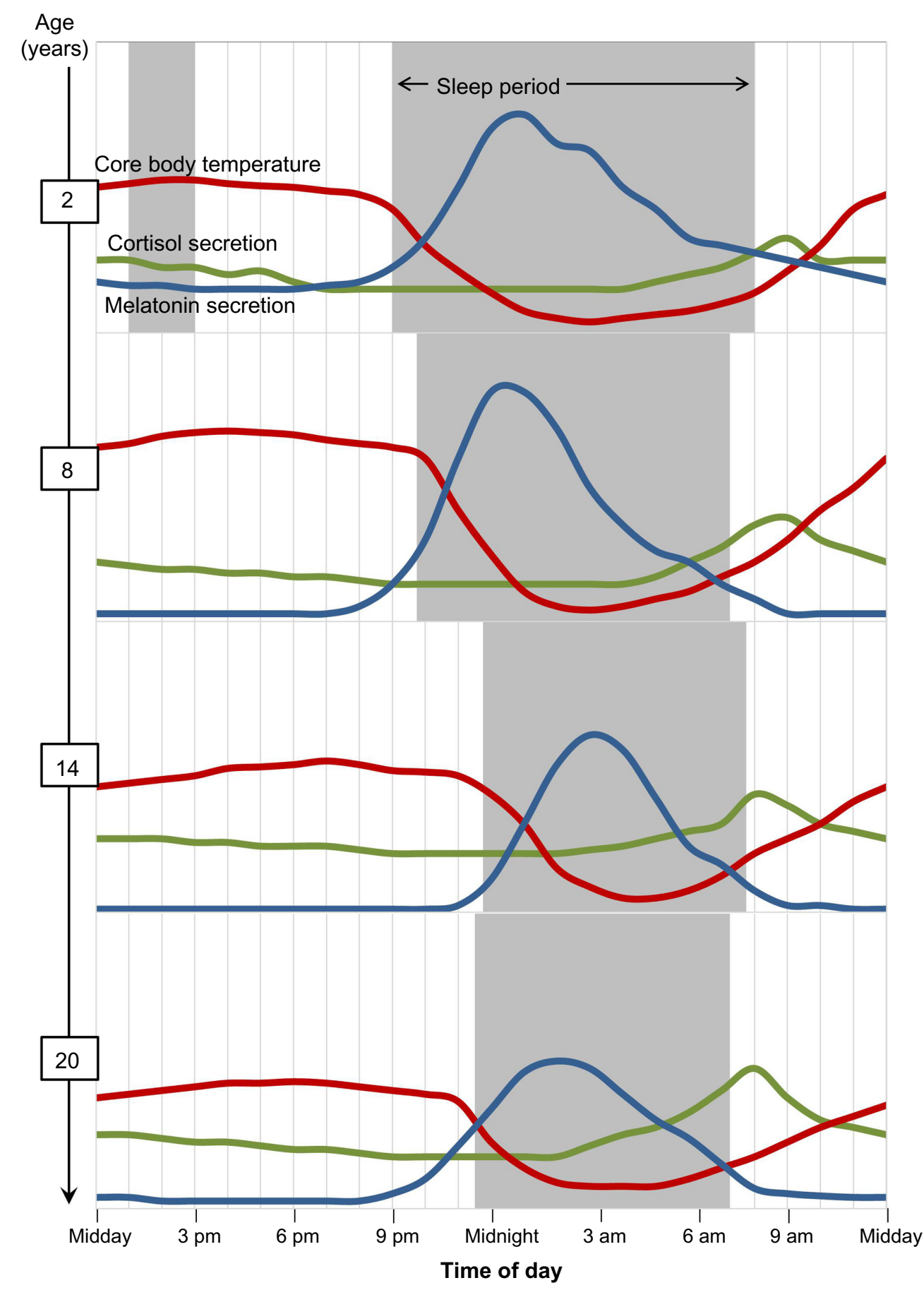

Figure I Illustration of changes in 24-hour rhythms of sleep-wake, melatonin secretion, cortisol secretion, and core body temperature from childhood to adulthood. 
Accompanying the sleep-wake cycle changes in adolescence is a shift of chronotype toward eveningness, ${ }^{8-10}$ ie, a greater preference for activities to be undertaken later in the day and for later bed and rise times. This shift toward eveningness is estimated to begin at 13 years of age, with a peak at 17-20 years for females and 20-21 years for males. ${ }^{11-13}$ The shift reverses - with a change back toward morningness - across adulthood..$^{13,14}$

As discussed in the following sections, the sleep-wake cycle changes taking place during childhood and adolescence are influenced by close interactions between a range of neuroendocrine, environmental, occupational, and behavioral factors, and may increase vulnerability to the development of mental and physical illnesses.

\section{Factors modulating developmental changes in the sleep-wake cycle Circadian rhythms and neuroendocrine factors}

Changes in endogenous circadian rhythms are a potential driver of the sleep-wake changes seen across development. The mammalian sleep-wake cycle is accompanied by intrinsic circadian rhythms of gene expression, metabolic function, temperature, and hormone production, driven by a complex system of internal pacemakers, environmental inputs, and feedback loops. ${ }^{15-19}$ Measurable outputs of endogenous rhythms such as hormone secretion and body temperature undergo changes across development. Phase delays during adolescence are also displayed in several non-human mammal species,${ }^{20}$ indicating that the phenomenon is likely driven by some common feature of mammalian biology. There are several plausible theoretical explanations linking changes in endogenous rhythms with the sleep-wake changes seen across development.

The pineal hormone melatonin plays a key role in the regulation of the sleep-wake cycle and follows a 24-hour pattern of secretion, with an evening onset, a nocturnal peak, and a decrease in the morning. ${ }^{21}$ The daily rhythm of melatonin secretion is not present at birth, but develops in the 1st months of life, ${ }^{22-25}$ is strongest at around 4-7 years of age and then steadily decreases in amplitude across the lifespan. ${ }^{26-28}$ In adolescence, the onset and offset of melatonin secretion have been shown to be delayed with increasing age and throughout pubertal development. ${ }^{29} \mathrm{~A}$ later onset of melatonin secretion in the evening is likely to contribute to sleep initiation difficulties and delayed sleep onset. Accordingly, between $7 \%$ and $36 \%$ of adolescents report difficulty falling asleep, while $20 \%-26 \%$ report a sleep onset latency greater than 30 minutes. ${ }^{30}$ In addition, administration of afternoon/ evening melatonin to adolescents has been demonstrated to successfully advance the phase of circadian rhythms and sleep timing. ${ }^{31}$

Cortisol secretion also follows a strong circadian rhythm, with high levels upon morning awakening, increasing to a peak about 30 minutes after awakening, then decreasing across the day to the lowest levels around bedtime. ${ }^{32,33}$ The circadian rhythm of cortisol secretion develops during the 1st year of life, and is associated with the establishment of a consolidated sleep-wake cycle. ${ }^{34-36}$ Alongside the decrease in napping across the first 3 years of life, the decrease of cortisol across the day smoothens and follows a slope more similar to that of adults. ${ }^{32}$ Across adolescence, cortisol levels increase and follow a flatter rhythm with age and pubertal development. ${ }^{37,38}$ A sex difference also emerges across adolescence, with higher morning cortisol levels in girls, likely related to gonadal changes associated with pubertal development. ${ }^{37,39,40} \mathrm{~A}$ bidirectional relationship between the timing and length of sleep and cortisol patterns in adolescents has been reported with a steeper decline in cortisol across the day associated with longer sleep. ${ }^{41}$

A circadian rhythm of core body temperature (CBT) is established in the 1st year of life, showing a peak during the day and a drop to a trough at night between 1 and 6 hours after sleep onset. ${ }^{42-45}$ This rhythm has a greater amplitude in children (between 7 months and 7 years old) than in adults. ${ }^{42}$ Later timing of the CBT rhythm has been associated with eveningness in adolescents and adults, ${ }^{46,47}$ and the rhythm has been reported to shift to an earlier phase across adulthood. ${ }^{48}$ Data on changes in the CBT rhythm across adolescence are lacking, but a report on three case studies suggests that the rhythm may delay across this period. ${ }^{49}$

Another potential influential factor is pubertal maturation, which is reported to be associated with both the adolescent decrease in sleep duration and the delay in sleep onset. ${ }^{50}$ Decreases in sleep duration have also been shown to predict pubertal changes longitudinally. ${ }^{50}$ Thus, it follows that pubertal hormones may be linked to these adolescent sleep-wake and circadian rhythm changes. A recent review by Hagenauer and Lee ${ }^{51}$ examines the evidence that the development of adolescent sleep-wake cycles and reproductive hormone secretion are bidirectionally related. Although most of the evidence for this relationship comes from animal studies, there is reason to believe that human circadian and reproductive systems are closely linked, with the biological clock regulating the timing of reproductive events such 
as hormone release and ovulation, and gonadal hormones influencing circadian parameters such as photic sensitivity and activity levels and timing. As such, development of one system in adolescence is likely to influence the other to some degree. The chronotype shift toward eveningness in adolescence has also been shown to be related to pubertal development ${ }^{14,52}$ and to increases in testosterone. ${ }^{53}$

The changes observed in the sleep-wake cycle, hormone secretion, and temperature rhythms may be explained by a variety of other factors. For instance, a lengthening of the intrinsic circadian phase would drive later timing of hormone secretion, which may in turn promote later sleep and wake times. In support of this, a study by Carskadon et $\mathrm{al}^{54}$ in which participants were maintained on a 28-hour day (forced desynchrony protocol) suggested that the intrinsic circadian period length in adolescents was approximately 24.3 hours, which is longer than some, but not all, reported intrinsic phases for adults. These results should be taken as preliminary given the small sample size (five boys and five girls), and no replication has yet been done. In addition, behavioral changes and other environmental influences (such as light exposure) may feed back into the internal timing system to elicit a shift in the internal pacemaker. More complex interactions between internal and external factors may also play a role, for example, changes in sensitivity of the internal pacemaker to light has been suggested as a possible mechanism for the phase delay in adolescence. ${ }^{55}$

In conjunction with the chronobiological and pubertal maturation perspectives, a recent homeostasis model proposed by Hagenauer and Lee ${ }^{20}$ provides another possible account of delays in sleep-wake timing and shortening of sleep length. According to the model, a decrease in the buildup of sleep pressure across the day and in its dissipation across the night predicts the observed delay in sleep-wake timing and shortening of duration. ${ }^{20}$ The findings of Jenni et $\mathrm{al}^{56}$ provide support for a slower buildup of sleep pressure based on changes in waking slow wave activity across adolescence; however, no changes were found in slow wave activity during sleep. Another theoretical model proposed by Phillips et $\mathrm{al}^{57}$ integrates several parameters to represent influences of circadian and homeostatic processes on neuronal firing and resultant circadian preference. This model explains the shift to eveningness in adolescence by a reduced strength of the homeostatic drive relative to the circadian drive.

\section{Environmental factors}

Human circadian rhythms are entrained to a 24-hour cycle by various environmental cues, the most influential of which is light. ${ }^{58,59}$ Exposure to morning light typically advances circadian phase, whereas exposure to evening light typically results in a delay. ${ }^{60,61}$ Thus, increased evening light exposure and decreased morning light exposure may contribute to the phase delays experienced in adolescence. In support of this, evening light exposure has been shown to correlate with eveningness in adolescents, ${ }^{62}$ and adolescents without electric lighting have been shown to have earlier sleep onset times. ${ }^{63}$ Although other factors may be at play (eg, cultural and occupational differences, absence of technology in those without electric lighting), this provides preliminary evidence for a role of light exposure in adolescent phase delays. On the other hand, changes in endogenous circadian rhythms may drive behavior leading to altered light exposure patterns. For example, a delay in endogenous phase may lead to later bedtimes as well as encouraging later light schedules. An alternative hypothesis is that adolescents experience an increased sensitivity to evening light and a decreased sensitivity to morning light. ${ }^{55}$

Various other environmental and behavioral factors have been proposed as contributors to sleep-wake and circadian changes in adolescence. Increasing academic and social demands are thought to be implicated in the extension of waking activity into the evening and subsequent delay and shortening of the sleep period. ${ }^{8,64,65}$ Increased use of electronic media seems to have a similar effect. ${ }^{66,67}$ The decrease in parentally set bedtimes has a noteworthy effect, with significantly later bedtime and shorter sleep duration in those without parent-set bedtimes. ${ }^{68}$ Another contributing factor is working status, with adolescents who engage in employment displaying shorter sleep durations and increased daytime sleepiness compared to their non-working peers. ${ }^{69-71}$ Fischer et $\mathrm{al}^{71}$ also found shorter adolescent sleep duration to be related to increased smoking and drinking behavior. Many of these environmental and behavioral factors relate to social and emotional maturation and increased independence, and are likely to interact with the biological factors described above in influencing sleep-wake and circadian changes. In addition, several environmental factors are known to influence chronotype, including photoperiod at birth, geographical location, and daylight savings time..$^{72,73}$ As such, age-related chronotype and sleep-wake changes may be differentially influenced by multiple factors, with potentially complex interactions.

\section{Occupational constraints: school schedules}

There is evidence to suggest that the restrictions imposed by school schedules may be a key driver in the shortening 
of sleep duration across childhood and adolescence. If it is assumed that the steady delay in sleep onset is part of a delay in the whole 24-hour sleep-wake cycle, it is reasonable to believe that forced wake-up times may be cutting short the sleep period. In support of this, studies comparing weekend sleep durations across adolescence have found no differences with increasing age, ${ }^{74,75}$ thus, the shortened duration is likely to be specific to factors present only on weekdays. Further, in countries with earlier school starting times, adolescent sleep duration is reported to be shorter. ${ }^{5}$ This influence of school schedule on sleep duration is supported by one meta-analysis of objective measures (polysomnography and actigraphy) that found total sleep time decreased across adolescence only when the measures were taken on school days. ${ }^{76}$ In contrast, a meta-analysis of subjective measures (self- or proxy-report based studies) noted a significant decline in both school and nonschool day sleep duration with increasing age, although the school day decline was significantly steeper than the non-school day decline. ${ }^{5}$

On weekends, both bed and wake times are reported to become later with increasing age across adolescence. ${ }^{77}$ This is accompanied by a greater disparity between sleep duration on school and non-school days, resulting in lengthier sleep episodes on weekends (a 25 -minute difference at age 9 increasing to an 86-minute difference at age 18).,78-80 This pattern becomes significant at age $9,{ }^{7}$ and is related to pubertal development. ${ }^{81}$ This difference between weekday and weekend sleep duration does not appear to be present during vacation from school, and overall sleep duration is longer in these vacation periods. ${ }^{82}$ As such, it is likely that during the school week, adolescents obtain inadequate amounts of sleep, driving them to "catch-up" on weekends and vacation periods. This is accompanied by increased daytime sleepiness across adolescence with increasing age, ${ }^{83-85}$ and increasing pubertal development. ${ }^{86}$ The increase in sleepiness has been related to later bedtimes and shorter sleep times; however, it is also reported to occur in the absence of sleep deprivation. ${ }^{86,87}$ Thus, it remains to be established whether this increase in sleepiness is a direct consequence of inadequate sleep or related to some other factor such as changes in the sleep homeostatic system. Adolescents also experience an increase in naps, ${ }^{3,88}$ which may form part of the catch-up sleep phenomenon. In adults with evening chronotypes, an analogous weekend catch-up pattern is observed in response to work schedules. ${ }^{89,90}$

The adolescent delayed sleep-wake pattern on weekends appears to be accompanied by a delay in endogenous circadian rhythms (as measured by dim light melatonin onset) ${ }^{80}$ This indicates that the behavioral shift of sleepwake phase may occur in conjunction with a neurobiological shift, making it more difficult for the students to return to an earlier phase upon their return to school the following week. The resulting misalignment between internal circadian phase and occupational schedule is termed "social jet lag", and is associated with elevated risk for negative mental and physical health outcomes. ${ }^{91}$ For most individuals, phase advances (shifts to earlier times) are more difficult to achieve than phase delays (shifts to later times); ${ }^{58,92}$ thus, the weekend catch-up sleep phenomenon may be detrimental to students' functioning. In line with this, both shorter school night sleep duration and greater disparity between weekday and weekend sleep times have been associated with poorer academic performance, increased daytime sleepiness, greater emotional distress, more risk taking behavior, and increased depressive symptoms. ${ }^{93-96}$ Further, experimental extension of sleep duration in adolescents has been shown to improve aspects of cognitive performance. ${ }^{97}$ In addition, eveningness is associated with higher cognitive abilities, yet is also related to poorer academic achievement, ${ }^{98,99}$ indicating that the scheduling of current educational activities may not be conducive to maximizing potential.

Educational programs designed to improve sleep in adolescents by encouraging better sleep habits have generally failed to produce sustainable behavioral changes. ${ }^{100}$ However, delays in school start times have been reported to result in increased sleep duration, increased school attendance, improved motivation, decreased daytime sleepiness, and fewer mood symptoms. ${ }^{101,102}$ This evidence provides a promising avenue for policy change to adjust school scheduling in accordance with neurodevelopmental changes in the sleep-wake cycle and improve adolescent health and functional outcomes.

\section{Behavioral factors: physical activity and eating behaviors}

Physical activity peaks in mid-childhood and decreases across adolescence. ${ }^{103-105}$ In particular, time spent engaging in moderate and vigorous physical activity is reported to decrease across childhood and early adolescence in both cross-sectional and longitudinal studies. ${ }^{106-108}$ The decline across adolescence (from 11 to 16 years) has been found to be steeper than that of childhood (from 6 to 9 years) and is accompanied by an increase in sedentary time. ${ }^{106}$ Evidence suggests that levels of physical activity remain low, or decrease further, into adulthood. ${ }^{105,106,108,109}$ 
Increased sedentary behavior and decreased physical activity has been associated with poorer fitness, ${ }^{110}$ increased risk for obesity, diabetes, and cardiovascular disease, ${ }^{11-114}$ and increased incidence of psychiatric disorders, ${ }^{115,116}$ making this an area of critical health concern.

The timing of the adolescent decline in physical activity corresponds to that of the sleep-wake cycle changes and as such may form part of an overall change in 24-hour sleep and activity patterns. Several lines of evidence support close relations between sleep changes and activity changes across this developmental period. In one study, greater sedentary time was found in adolescents with sleep durations of less than 8 hours. ${ }^{117}$ In another study, 10-12 years old who slept less than 9 hours were less active than those sleeping 10 or more hours, and in addition, those engaging in weekend catch-up sleep were reported to be less active. ${ }^{118}$ In a third study, the frequency and duration of exercise bouts in 9-11 years old was found to be greater on weekdays than weekend days. ${ }^{119}$ These findings may reflect interacting disruptions in the regularity of sleep, wake, and activity patterns, which may have detrimental effects on health and functioning. A clear example of the effect of activity levels on sleep and functioning parameters comes from Brand et al, ${ }^{120}$ who compared adolescent athletes to controls and found that the athletes (who spent an average of over 17 hours per week exercising vs less than 5 hours in the controls) reported higher sleep quality, shorter sleep onset latency, fewer awakenings after sleep onset, less daytime tiredness, and increased concentration, as well as fewer anxiety and depressive symptoms.

Later timing of sleep and wake, as well as greater eveningness has also been associated with decreased physical activity and increased screen time (computer/television use) in adolescence, as well as poorer attitudes toward physical activity. ${ }^{121-123}$ There is some evidence for a continuation of this relationship between sleep timing, chronotype, and physical activity into adulthood, with lower levels of physical activity in adults who have later sleep times ${ }^{124}$ and a propensity for morningness in adult athletes. ${ }^{125}$ It is thus important to consider both daytime activity patterns and sleep patterns as part of an overall 24-hour cycle and contributions of this to adverse health outcomes.

The sleep-wake cycle changes in adolescence are also associated with changes in diet and related health factors. Adolescents with shorter sleep durations present with unhealthy dieting behaviors ${ }^{126}$ and are less likely to eat adequate fruit, vegetables, and fish. ${ }^{117}$ Short sleep duration is also associated with higher body mass index, body fat, and waist and hip circumferences in adolescents, ${ }^{117}$ and with an increased risk for obesity in both children and adults. ${ }^{127}$ Experimentally restricted sleep duration in adolescents has been shown to result in consumption of foods with higher glycemic indices, ${ }^{128}$ indicating that shortened sleep may contribute to poorer food choices. Obese children and adolescents are also reported to have a greater incidence of sleep disordered breathing, ${ }^{129-131}$ which may cause fragmented sleep and increased daytime sleepiness, thus disruption of the rest-activity cycle. Children and adolescents with late bed and wake times have also been shown to have poorer diet quality, a higher intake of energy-dense, nutrient poor foods, and reduced consumption of fruit and vegetables independent of sleep duration. ${ }^{132}$ There also appear to be similar effects of chronotype, with reports of increased consumption of fast food $^{133}$ and longitudinal increases in body mass index ${ }^{134}$ in adolescents with evening chronotypes. The negative associations between sleep-wake factors and eating behaviors continue into adulthood with less fruit and vegetable consumption and more calories consumed after $8 \mathrm{pm}$ in those with later bed and wake times. ${ }^{135}$

Further to behavioral changes in diet with increasing age, changes in the internal circadian timing system can have effects on metabolic processes, such as the timing of glucose metabolism and cardiovascular function. ${ }^{16,136}$ Thus, circadian misalignment, as seen in social jetlag, can have detrimental effects on health, with increased risk of obesity, insulin resistance, and hypertension. ${ }^{16,136}$ Conversely, the timing of food consumption feeds back into the internal timing system and can itself promote changes in endogenous circadian rhythms. ${ }^{136}$ This reinforces the importance of maintaining regularity in sleep-wake behaviors, and eating behaviors, as well as maintaining a schedule in line with internal circadian phase.

\section{Deviation from normal developmental changes Delayed sleep phase disorder}

A potential deviation from normal developmental changes of the sleep-wake cycle can be seen in delayed sleep phase disorder (DSPD). This condition is characterized by severely delayed timing of sleep onset and offset, increased daytime tiredness, and consequent impairment in daytime functioning, and has typical onset in childhood or adolescence. ${ }^{137,138}$ The disorder may represent an exaggerated case of the delay that occurs across development, and as such may be a malfunction of the normal maturational development of sleep and activity patterns. DSPD is also linked to abnormalities in endogenous rhythms, with a delay of melatonin secretion and 
CBT accompanying the delay in sleep-wake patterns. ${ }^{139-144}$ Additionally, evening exogenous melatonin administration has been demonstrated as an effective treatment for this disorder. ${ }^{145-147}$ DSPD is associated with various functional difficulties (such as failure to attend school) ${ }^{137,148}$ as well as increased incidence of depressive symptoms. ${ }^{137,149}$ As such, screening to identify individuals with exaggerated or abnormal changes in sleep-wake cycles during childhood and adolescence may prove useful in early intervention and prevention for DSPD.

\section{Mental illness}

Deviations from normal developmental sleep-wake changes may also form risk factors for adverse mental health outcomes. In one instance, shortened sleep duration is found in several neurodevelopmental and mental disorders including mood disorders, anxiety disorders, attention deficit hyperactivity disorder (ADHD), schizophrenia, and alcohol dependence. ${ }^{150-153}$ Similarly, a delay in timing of the sleep-wake cycle (including delayed sleep onset and offset) has been associated with anxiety disorders, depression, bipolar disorder, seasonal affective disorder, and psychotic disorders. ${ }^{154-158}$ Various disturbances in sleep are found in mental disorders: increased sleep latency, awakenings, limb movement disorders, and sleep disordered breathing in ADHD; ${ }^{159,160}$ increased sleep latency, awakenings, nightmares, and night time panic attacks in anxiety disorders ${ }^{161-163}$ increased sleep latency and awakenings in affective disorders; ${ }^{162,164,165}$ irregular and fragmented sleep in psychotic disorders, ${ }^{166}$ and increased sleep latency, awakenings, and sleep disordered breathing in alcoholism. ${ }^{167,168}$ Increased daytime sleepiness is also found in ADHD and major depression. ${ }^{160,169,170}$ There is a period of increased onset of many of these mental illnesses during adolescence, ${ }^{171,172}$ which coincides with the period of increased change in sleep-wake patterns outlined above. An increased incidence of depressive symptoms is also found in children and adults with sleep disordered breathing ${ }^{173-175}$ which may reflect, among other possible pathophysiological mechanisms, an influence of disruption in the sleep-wake cycle on the development of mental illness. Sleep-wake changes have been indicated as prodromal symptoms for several mental disorders ${ }^{164,176-178}$ and have been shown to worsen in more severe and persistent illness phases. ${ }^{179,180}$ Thus, anomalous changes in sleep and activity patterns across childhood and adolescence may form part of the etiology of these conditions and should be considered as a potential risk factor.
In conjunction with changes in the timing and length of sleep, irregularities of 24-hour sleep and activity patterns have been implicated as risk or causal factors for mental illness. For example, seasonal affective disorder and nonseasonal depression have been associated with a lower amplitude of circadian activity rhythms in children. ${ }^{181,182}$ Irregularity of these patterns has also been demonstrated in both bipolar disorder ${ }^{183}$ and ADHD. ${ }^{184}$ These two disorders are characterized by abnormally elevated activity levels, which may be reflective of failure to develop a regular pattern of sleep and activity. There is also evidence of increased variability and reduced stability of sleep-wake cycles in those at high risk for bipolar disorder, ${ }^{176}$ as well as longitudinal evidence that irregularity of sleep-wake patterns in childhood is associated with increased behavioral difficulties, ${ }^{185}$ and incidence of depressive and anxious disorders in adolescence and adulthood. ${ }^{186}$ Symptoms themselves show time of day variations, including hyperactivity and inattention in ADHD, ${ }^{160}$ as well as mood in both healthy and mood disordered patients. ${ }^{187-189}$

Disruption of endogenous biological rhythms likely contributes to behavioral abnormalities in sleep and activity patterns, and may also play a role in the development of mental illnesses. Elevated cortisol levels in adolescence have been implicated in the development of several mental illnesses including anxiety, ${ }^{190}$ schizophrenia, ${ }^{191}$ and affective disorders. ${ }^{192}$ Major depression has been shown to be associated with elevated cortisol levels in the evening. ${ }^{193,194}$ Bipolar disorder has also been associated with abnormalities in cortisol secretion, with elevated levels in manic, depressive, and euthymic states. ${ }^{195}$ Abnormalities in melatonin secretion are found across several diagnostic subgroups of psychiatric patients, including those with mood, ${ }^{196-199}$ anxiety, ${ }^{200}$ and psychotic ${ }^{201-203}$ disorders. There is also some evidence to suggest a desynchrony between endogenous melatonin rhythms and rest-activity cycles in young people with mood disorders. ${ }^{91,199}$ Further, interventions that target the melatonin system have shown promise in treatment of mood disorders. ${ }^{204-206}$ In ADHD, there is some evidence for a delay of melatonin rhythms in children and adults with comorbid insomnia, and abnormal patterns of cortisol secretion have been reported in children. ${ }^{160}$ However, results are mixed on the direction of deviations and roles of comorbid factors, and a specific role of endogenous rhythm disruptions in ADHD remains to be established. ${ }^{160}$ Circadian gene polymorphisms and circadian gene expression have been implicated in the development of anxiety disorders, affective disorders, psychotic disorders, ADHD, and alcoholism, ${ }^{207-216}$ further 
supporting a role of circadian systems in neurodevelopmental and mental disorders.

\section{Conclusion}

The developmental period between childhood and adulthood involves changes in the sleep-wake cycle, and the circadian rhythm of rest and activity, most notably a delay in sleep onset and shortening of sleep duration. Several environmental and biological factors appear to contribute to these changes, including the maturation of neuroendocrine systems, school schedules, and light exposure. There is potential to improve adolescent functioning and academic performance with informed adjustments of school schedules. Changes in the sleep-wake cycle and circadian rhythms are also associated with various aspects of physical activity, eating behaviors, and physical and mental health, and thus represent important factors to consider in investigations of the etiology and treatment of mental and physical illnesses. Current understanding of these areas would benefit from longitudinal research into specific causal relationships between rest and activity patterns and the development of mental and physical illnesses. The efficacy of treatments for mood disorders targeting the melatonin system illustrates the value of considering sleep-wake and circadian systems in the development of novel treatments; further expansion of this area will be of considerable interest. Future research should also consider the potential utility of screening to identify individuals with abnormal development of sleep-wake cycles and the possible effectiveness of sleep and circadian-based prevention and intervention strategies in relation to health outcomes.

\section{Disclosure}

The authors would like to declare the following conflicts of interest: IBH is a Commissioner in Australia's new National Mental Health Commission from 2012. He was a director of headspace: the national youth mental health foundation until January 2012. He was previously the chief executive officer (till 2003) and clinical adviser (till 2006) of beyond blue, an Australian National Depression Initiative. He is the executive director of the Brain and Mind Research Institute, which operates two early-intervention youth services under contract to headspace. He has led a range of community-based and pharmaceutical industry-supported depression awareness and education and training programs. He has led projects for health professionals and the community supported by governmental, community agency and pharmaceutical industry partners (Wyeth, Eli Lily, Servier, Pfizer, and AstraZeneca) for the identification and management of depression and anxiety. He has received honoraria for presentations of his own work at educational seminars supported by a number of non-government organizations and the pharmaceutical industry (including Servier, Pfizer, AstraZeneca, and Eli Lilly). He is a member of the Medical Advisory Panel for Medibank Private and also a Board Member of Psychosis Australia Trust. He leads an investigator-initiated study of the effects of agomelatine on circadian parameters (supported in part by Servier) and has participated in a multicenter clinical trial of the effects of agomelatine on sleep architecture in depression and a Servier-supported study of major depression and sleep disturbance in primary care settings.

The authors also note the following financial disclosures: IBH was funded by a National Health and Medical Research Council Program Grant (No 566529) and Australian Fellowship (No 464914). RR received a postdoctoral training award from the Fonds de la recherche en sante du Quebec. JSC was supported by the NHMRC Centre of Research Excellence in Optimising Early Interventions for Young People with Emerging Mood Disorders (No 1061043). The funders had no role in the decision to publish, or preparation of this manuscript.

\section{References}

1. Coons S, Guilleminault C. Development of consolidated sleep and wakeful periods in relation to the day/night cycle in infancy. Dev Med Child Neurol. 1984;26:169-176.

2. Iglowstein I, Jenni OG, Molinari L, Largo RH. Sleep duration from infancy to adolescence: reference values and generational trends. Pediatrics. 2003;111(2):302-307.

3. Seo WS, Sung HM, Lee JH, et al. Sleep patterns and their agerelated changes in elementary-school children. Sleep Med Rev. 2010; 11(6):569-575.

4. Galland BC, Taylor BJ, Elder DE, Herbison P. Normal sleep patterns in infants and children: a systematic review of observational studies. Sleep Med Rev. 2012;16(3):213-222.

5. Olds T, Blunden S, Petkov J, Forchino F. The relationships between sex, age, geography and time in bed in adolescents: a meta-analysis of data from 23 countries. Sleep Med Rev. 2010;14(6):371-378.

6. Ohayon MM, Roberts RE, Zulley J, Smirne S, Priest RG. Prevalence and patterns of problematic sleep among older adolescents. J Am Acad Child Adolesc Psychiatry. 2000;39(12):1549-1556.

7. Thorleifsdottir B, Bjomsson JK, Benediktsdottir B, Gislason T, Kristbjarnarson $\mathrm{H}$. Sleep and sleep habits from childhood to young adulthood over a 10-year period. J Psychosom Res. 2002;53:529-537.

8. Gau S, Soong W. The transition of sleep-wake patterns in early adolescence. Sleep. 2003;26(4):449-454.

9. Shinkoda H, Matsumoto K, Park YM, Nagashima H. Sleep-wake habits of schoolchildren according to grade. Psychiatry Clin Neurosci. 2000;54:287-289.

10. Díaz-Morales JF, Sorroche MG. Morningness-eveningness in adolescents. Span J Psychol. 2008;11(1):201-206.

11. Tonetti L, Fabbri M, Natale V. Sex difference in sleep-time preference and sleep need: a cross-sectional survey among Italian preadolescents, adolescents, and adults. Chronobiol Int. 2008;25(5): 745-759. 
12. Kim S, Dueker GL, Hasher L, Goldstein D. Children's time of day preference: age, gender and ethnic differences. Pers Individ Differ. 2002;33:1083-1090.

13. Roenneberg T, Kuehnle T, Pramstaller PP, et al. A marker for the end of adolescence. Curr Biol. 2004;14(24):R1038-R1039.

14. Randler C. Age and gender differences in morningness-eveningness during adolescence. J Genet Psychol. 2011;172(3):302-308.

15. Ko CH, Takahashi JS. Molecular components of the mammalian circadian clock. Hum Mol Genet. 2006;15 Spec No 2:R271-R277.

16. Kalsbeek A, Scheer FA, Perreau-Lenz S, et al. Circadian disruption and SCN control of energy metabolism. FEBS Lett. 2011;585(10): 1412-1426.

17. Albrecht U, Eichele G. The mammalian circadian clock. Curr Opin Genet Dev. 2003;13(3):271-277.

18. Schibler U. The daily timing of gene expression and physiology in mammals. Dialogues Clin. Neurosci. 2007;9(3):257-272.

19. Saper CB. The central circadian timing system. Curr Opin Neurobiol. 2013;23(5):747-751

20. Hagenauer MH, Lee TM. Adolescent sleep patterns in humans and laboratory animals. Horm. Behav. 2013;64(2):270-279.

21. Cajochen C, Krauchi K, Wirz-Justice A. Role of melatonin in the regulation of human circadian rhythms and sleep. J Neuroendocrinol. 2003;15:432-437.

22. Attanasio A, Rager K, Gupta D. Ontogeny of circadian rhythmicity for melatonin, serotonin, and $\mathrm{N}$-acetylserotonin in humans. J Pineal Res 1986;3:251-256.

23. Ardura J, Gutierrez R, Andres J, Agapito T. Emergence and evolution of the circadian rhythm of melatonin in children. Horm Res. 2005; 59(2):66-72.

24. Kennaway DJ, Goble FC, Stamp GE. Factors influencing the development of melatonin rhythmicity in humans. J Clin Endocrinol Metab. 1996;81(4):1525-1532.

25. Kennaway DJ, Stamp GE, Goble FC. Development of melatonin production in infants and the impact of prematurity. J Clin Endocrinol Metab. 1992;75(2):367-369.

26. Iguchi H, Kato K-I, Ibayashi H. Age-dependent reduction in serum melatonin concentrations in healthy human subjects. J Clin Endocrinol Metab. 1982;55(1):27-29.

27. Attanasio A, Borrelli P, Gupta D. Circadian rhythms in serum melatonin from infancy to adolescence. J Clin Endocrinol Metab. 1985;61(2):388-390.

28. Commentz JC, Uhlig H, Henke A, Hellwege HH, Willig RP. Melatonin and 6-hydroxymelatonin sulfate excretion is inversely correlated with gonadal development in children. Horm Res. 1997;47(3):97-101.

29. Carskadon MA, Acebo C, Richardson GS, Tate BA, Seifer R. An approach to studying circadian rhythms of adolescent humans. J Biol Rhythms. 1997;12(3):278-289.

30. Gradisar M, Gardner G, Dohnt H. Recent worldwide sleep patterns and problems during adolescence: a review and meta-analysis of age, region, and sleep. Sleep Med Rev. 2011;12(2):110-118.

31. Eckerberg B, Lowden A, Nagai R, Akerstedt T. Melatonin treatment effects on adolescent students' sleep timing and sleepiness in a placebo-controlled crossover study. Chronobiol Int. 2012;29(9): 1239-1248.

32. Watamura SE, Donzella B, Kertes DA, Gunnar MR. Developmental changes in baseline cortisol activity in early childhood: relations with napping and effortful control. Dev Psychobiol. 2004;45(3): 125-133.

33. Pruessner JC, Wolf OT, Hellhammer DH, et al. Free cortisol levels after awakening: a reliable biological marker for the assessment of adrenocortical activity. Life Sci. 1997;61(26):2539-2549.

34. de Weerth C, Zij1 RH, Buitelaar JK. Development of cortisol circadian rhythm in infancy. Early Hum Dev. 2003;73(1-2):39-52.

35. Spangler G. The emergence of adrenocortical circadian function in newborns and infants and its relationship to sleep, feeding and maternal adrenocortical activity. Early Hum Dev. 1991;25: 197-208.
36. Onishi S, Miyazawa G, Nishimura Y, et al. Postnatal development of circadian rhythm in serum cortisol levels in children. Pediatrics. 1983;72(3):399-404.

37. Shirtcliff EA, Allison AL, Armstrong JM, Slattery MJ, Kalin NH, Essex MJ. Longitudinal stability and developmental properties of salivary cortisol levels and circadian rhythms from childhood to adolescence. Dev Psychobiol. 2012;54(5):493-502.

38. Kiess W, Meidert A, Dressendorfer RA, et al. Salivary cortisol levels throughout childhood and adolescence: relation with age, pubertal stage, and weight. Pediatr Res. 1995;37(4):502-506.

39. Netherton C. Salivary cortisol and dehydroepiandrosterone in relation to puberty and gender. Psychoneuroendocrinology. 2004;29(2): 125-140.

40. Oskis A, Loveday C, Hucklebridge F, Thorn L, Clow A. Diurnal patterns of salivary cortisol across the adolescent period in healthy females. Psychoneuroendocrinology. 2009;34(3):307-316.

41. Zeiders KH, Doane LD, Adam EK. Reciprocal relations between objectively measured sleep patterns and diurnal cortisol rhythms in late adolescence. J Adolesc Health. 2011;48(6):566-571.

42. Abe K, Sasaki H, Takebayashi K, Fukui S, Nambu H. The development of circadian rhythm of human body temperature. J Interdiscipl Cycle Res. 1978;9(3):211-216.

43. Wailoo MP, Petersen SA, Whittaker H, Goodenough P. Sleeping body temperatures in 3-4 month old infants. Arch Dis Child. 1989;64: 596-599.

44. Glotzbach SF, Edgar DM, Boeddiker M, Ariagno RL. Biological rhythmicity in normal infants during the first 3 months of life. Paediatrics. 1994;94(4):482-488.

45. Lodemore M, Petersen SA, Wailoo MP. Development of night time temperature rhythms over the first six months of life. Arch Dis Child. 1991;66:521-524.

46. Baehr EK, Revelle W, Eastman CI. Individual differences in the phase and amplitude of the human circadian temperature rhythm: with an emphasis on morningness-eveningness. J Sleep Res. 2000;9 $117-127$.

47. Andrade MM, Benedito-Silva AA, Menna-Barreto L. Correlations between morningness-eveningness character, sleep habits and temperature rhythm in adolescents. Braz J Med Biol Res. 1992;25(8): 835-839.

48. Carrier J, Paquet J, Morettini J, Touchette E. Phase advance of sleep and temperature circadian rhythms in the middle years of life in humans. Neurosci Lett. 2002;320:1-4.

49. Ishihara K. Development of body temperature rhythm: 6 years follow up of three cases. Psychiatry Clin Neurosci. 2001;55:229-230.

50. Sadeh A, Dahl RE, Shahar G, Rosenblat-Stein S. Sleep and the transition to adolescence: a longitudinal study. Sleep. 2009;32(12):1602-1609.

51. Hagenauer MH, Lee TM. The neuroendocrine control of the circadian system: adolescent chronotype. Front Neuroendocrinol. 2012; 33(3):211-229.

52. Carskadon MA, Vieira C, Acebo C. Association between puberty and delayed phase preference. Sleep. 1993;16(3):258-262.

53. Randler C, Ebenhoh N, Fischer A, et al. Chronotype but not sleep length is related to salivary testosterone in young adult men. Psychoneuroendocrinology. 2012;37(10):1740-1744.

54. Carskadon MA, Labyak SE, Acebo C, Seifer R. Intrinsic circadian period of adolescent humans measured in conditions of forced desynchrony. Neurosci Lett. 1999;260:129-132.

55. Hagenauer MH, Perryman JI, Lee TM, Carskadon MA. Adolescent changes in the homeostatic and circadian regulation of sleep. Dev Neurosci. 2009;31(4):276-284.

56. Jenni OG, Achermann P, Carskadon MA. Homeostatic sleep regulation in adolescents. Sleep. 2005;28(11):1446-1454.

57. Phillips AJ, Chen PY, Robinson PA. Probing the mechanisms of chronotype using quantitative modeling. J Biol Rhythms. 2010;25(3): 217-227.

58. Duffy JF, Wright KP Jr. Entrainment of the human circadian system by light. J Biol Rhythms. 2005;20(4):326-338. 
59. Boivin DB, Duffy JF, Kronauer RE, Czeisler CA. Dose-response relationships for resetting of human circadian clock by light. Nature. 1996;379:540-541.

60. Roenneberg T, Daan S, Merrow M. The art of entrainment. $J$ Biol Rhythms. 2003;18(3):183-194.

61. Goulet G, Mongrain V, Desrosiers C, Paquet J, Dumont M. Daily light exposure in morning-type and evening-type individuals. J Biol Rhythms. 2007;22(2):151-158.

62. Vollmer C, Michel U, Randler C. Outdoor light at night (LAN) is correlated with eveningness in adolescents. Chronobiol Int. 2012; 29(4):502-508.

63. Peixoto CA, da Silva AG, Carskadon MA, Louzada FM. Adolescents living in homes without electric lighting have earlier sleep times. Behav Sleep Med. 2009;7(2):73-80.

64. Hansen M, Janssen I, Schiff A, Zee PC, Dubocovich ML. The impact of school daily schedule on adolescent sleep. Pediatrics. 2005;115(6): $1555-1561$

65. Yang CK, Kim JK, Patel SR, Lee JH. Age-related changes in sleep/wake patterns among Korean teenagers. Pediatrics. 2005; 115(1 Suppl):250-256.

66. Cain N, Gradisar M. Electronic media use and sleep in school-aged children and adolescents: a review. Sleep Med Rev. 2010;11(8): 735-742.

67. Gamble AL, D'Rozario AL, Bartlett DJ, et al. Adolescent sleep patterns and night-time technology use: results of the Australian Broadcasting Corporation's big sleep survey. PLoS One. 2014;9(11):e111700.

68. Short MA, Gradisar M, Wright H, Lack LC, Dohnt H, Carskadon MA. Time for bed: parent-set bedtimes associated with improved sleep and daytime functioning in adolescents. Sleep. 2011;34(6):797-800.

69. Vinha D, Cavalcante JA, Andrade MMM. Sleep-wake patterns of student workers and non-workers. Biol Rhythm Res. 2002;33(4): $417-426$.

70. Teixeira LR, Fischer FM, Nagai R, Turte SL. Teen at work: the burden of a double shift on daily activities. Chronobiol Int. 2004;21(6): $845-858$.

71. Fischer FM, Nagai R, Teixeira LR. Explaining sleep duration in adolescents: the impact of socio-demographic and lifestyle factors and working status. Chronobiol Int. 2008;25(2-3):359-372.

72. Adan A, Archer SN, Hidalgo MP, Di Milia L, Natale V, Randler C. Circadian typology: a comprehensive review. Chronobiol Int. 2012; 29(9):1153-1175.

73. Kantermann T, Juda M, Merrow M, Roenneberg T. The human circadian clock's seasonal adjustment is disrupted by daylight saving time. Curr Biol. 2007;17(22):1996-2000.

74. Liu X, Zhao Z, Jia C, Buysse DJ. Sleep patterns and problems among chinese adolescents. Pediatrics. 2008;121(6):1165-1173.

75. Anders TF, Carskadon MA, Dement WC, Harvey K. Sleep habits of children and the identification of pathologically sleepy children. Child Psychiatry Hum Dev. 1978;9(1):56-63.

76. Ohayon MM, Carskadon MA, Guilleminault C, Vitiello MV. Metaanalysis of quantitative sleep parameters from childhood to old age in healthy individuals: developing normative sleep values across the human lifespan. Sleep. 2004;27(7):1255-1273.

77. Olds T, Maher C, Blunden S, Matricciana L. Normative data on the sleep habits of Australian children and adolescents. Sleep. 2010;33(10): 1381-1388.

78. Knutson K, Lauderdale DS. Sociodemographic and behavioral predictors of bed time and wake time among US adolescents aged 15 to 17 years. $J$ Pediatr. 2009; 154:426-430.

79. Russo PM, Bruni O, Lucidi F, Ferri R, Violani C. Sleep habits and circadian preference in Italian children and adolescents. $J$ Sleep Res. 2007; $16: 163-169$.

80. Crowley SJ, Carskadon MA. Modifications to weekend recovery sleep delay circadian phase in older adolescents. Chronobiol Int. 2010;27(7):1469-1492.

81. Laberge L, Petit D, Simard C, Vitaro F, Tremblay RE. Development of sleep patterns in early adolescence. $J$ Sleep Res. 2001;10:59-67.
82. Szymczak JT, Jasinska M, Pawlak E, Zwierzykowska M. Annual and weekly changes in the sleep-wake rhythm of school children. Sleep. 1993;16(5):433-435.

83. Campbell IG, Higgins LM, Trinidad JM, Richardson P, Feinberg I. The increase in longitudinally measured sleepiness across adolescence is related to the maturational decline in low-frequency EEG power. Sleep. 2007;30(12):1677-1687.

84. Giannotti F, Cortesi F, Sebastiani T, Ottaviano S. Circadian preference, sleep and daytime behaviour in adolescence. $J$ Sleep Res. 2002;11: 191-199.

85. Gibson ES, Powles AC, Thabane L, et al. "Sleepiness" is serious in adolescence: two surveys of 3235 Canadian students. BMC Public Health. 2006;6:116.

86. Carskadon MA, Harvey K, Duke P, Anders TF, Litt IF, Dement WC. Pubertal changes in daytime sleepiness. Sleep. 1980;2(4):453-460.

87. Carskadon MA, Orav EJ, Dement WC. Evolution of sleep and daytime sleepiness in adolescents. In: Guilleminault C, Lugaresi E, editors. Sleep/Wake Disorders: Natural History, Epidemiology, and Long-term Evolution. New York: Raven Press; 1983:201-216.

88. Park YM, Matsumoto K, Seo YS, Kang MJ, Nagashima H. Changes of sleep or waking habits by age and sex in Japanese. Percept Mot Skills. 2002;94:1199-1213.

89. Roenneberg T, Kuehnle T, Juda M, et al. Epidemiology of the human circadian clock. Sleep Med Rev. 2007;11(6):429-438.

90. Roenneberg T, Wirz-Justice A, Merrow M. Life between clocks: daily temporal patterns of human chronotypes. J Biol Rhythms. 2003;18(1):80-90

91. Baron KG, Reid KJ. Circadian misalignment and health. Int Rev Psychiatry. 2014;26(2):139-154.

92. Waterhouse J, Reilly T, Atkinson G, Edwards B. Jet lag: trends and coping strategies. Lancet. 2007;369(9567):1117-1129.

93. Haraszti RA, Ella K, Gyongyosi N, Roenneberg T, Kaldi K. Social jetlag negatively correlates with academic performance in undergraduates. Chronobiol Int. 2014;31(5):603-612.

94. Wolfson AR, Carskadon MA. Sleep schedules and daytime functioning in adolescents. Child Dev. 1998;69(4):875-887.

95. Asarnow LD, McGlinchey E, Harvey AG. The effects of bedtime and sleep duration on academic and emotional outcomes in a nationally representative sample of adolescents. $J$ Adolesc Health. 2014;54(3): 350-356.

96. O'Brien EM, Mindell JA. Sleep and risk-taking behavior in adolescents. Behav Sleep Med. 2005;3(3):113-133.

97. Dewald-Kaufmann JF, Oort FJ, Meijer AM. The effects of sleep extension on sleep and cognitive performance in adolescents with chronic sleep reduction: an experimental study. Sleep Med Rev. 2013;14(6):510-517.

98. Preckel F, Lipnevich AA, Schneider S, Roberts RD. Chronotype, cognitive abilities, and academic achievement: a meta-analytic investigation. Learn Individ Differ. 2011;21(5):483-492.

99. Díaz-Morales JF, Escribano C. Predicting school achievement: the role of inductive reasoning, sleep length and morningness-eveningness. Pers Individ Differ. 2013;55(2):106-111.

100. Cassoff J, Knauper B, Michaelsen S, Gruber R. School-based sleep promotion programs: effectiveness, feasibility and insights for future research. Sleep Med Rev. 2013;17(3):207-214.

101. Owens JA, Belon K, Moss P. Impact of delaying school start time on adolescent sleep, mood, and behavior. Arch Pediatr Adolesc Med. 2010;164(7):608-614.

102. Wahlstrom $\mathrm{K}$. Changing times: findings from the first longitudinal study of later high school start times. NASSP Bull. 2002;86(633): $3-21$.

103. Duncan SC, Duncan TE, Strycker LA, Chaumeton NR. A cohortsequential latent growth model of physical activity from ages 12 to 17 years. Ann Behav Med. 2007;33(1):80-89.

104. Findlay LC, Garner RE, Kohen DE. Children's organized physical activity patterns from childhood into adolescence. J Phys Act Health. 2009;6:708-715. 
105. Troiano RP, Berrigan D, Dodd KW, Masse LC, Tilert T, McDowell M. Physical activity in the United States measured by accelerometer. Med Sci Sports Exerc. 2008;40(1):181-188.

106. Arundell L, Ridgers ND, Veitch J, Salmon J, Hinkley T, Timperio A. 5 -Year changes in afterschool physical activity and sedentary behavior. Am J Prev Med. 2013;44(6):605-611.

107. Klinker CD, Schipperijn J, Christian H, Kerr J, Ersboll AK, Troelsen J. Using accelerometers and global positioning system devices to assess gender and age differences in children's school, transport, leisure and home based physical activity. Int J Behav Nutr Phys Act. 2014;11:8.

108. Nader PR, Bradley RH, Houts RM, McRitchie SL, O'Brien M. Moderate-to-vigorous physical activity from ages 9 to 15 years. JAMA. 2008;300(3):295-305.

109. Gordon-Larsen P, Nelson MC, Popkin BM. Longitudinal physical activity and sedentary behavior trends: adolescence to adulthood. Am J Prev Med. 2004;27(4):277-283.

110. Hardy LL, Dobbins TA, Denney-Wilson EA, Okely AD, Booth ML. Sedentariness, small-screen recreation, and fitness in youth. Am J Prev Med. 2009;36(2):120-125.

111. Edwardson CL, Gorely T, Davies MJ, et al. Association of sedentary behaviour with metabolic syndrome: a meta-analysis. PLoS One. 2012;7(4):e34916.

112. Nocon M, Hiemann T, Muller-Riemenschneider F, Thalau F, Roll S, Willich SN. Association of physical activity with all-cause and cardiovascular mortality: a systematic review and meta-analysis. Eur $J$ Cardiovasc Prev Rehabil. 2008;15(3):239-246.

113. Wilmot EG, Edwardson CL, Achana FA, et al. Sedentary time in adults and the association with diabetes, cardiovascular disease and death: systematic review and meta-analysis. Diabetologia. 2012;55(11): 2895-2905.

114. Must A, Tybor DJ. Physical activity and sedentary behavior: a review of longitudinal studies of weight and adiposity in youth. Int $J$ Obes. 2005;29:S84-S96.

115. Iannotti RJ, Wang J. Patterns of physical activity, sedentary behavior, and diet in US adolescents. $J$ Adolesc Health. 2013;53(2): 280-286.

116. Mangerud WL, Bjerkeset O, Lydersen S, Indredavik MS. Physical activity in adolescents with psychiatric disorders and in the general population. Child Adolesc Psychiatry Ment Health. 2014;8(1):2.

117. Garaulet M, Ortega FB, Ruiz JR, et al. Short sleep duration is associated with increased obesity markers in European adolescents: effect of physical activity and dietary habits. The HELENA study. Int $J$ Obes. 2011;35(10):1308-1317.

118. Stone MR, Stevens D, Faulkner GE. Maintaining recommended sleep throughout the week is associated with increased physical activity in children. Prev Med. 2013;56(2):112-117.

119. Rowlands AV, Pilgrim EL, Eston RG. Patterns of habitual activity across weekdays and weekend days in 9-11-year-old children. Prev Med. 2008;46(4):317-324.

120. Brand S, Gerber M, Beck J, Hatzinger M, Puhse U, Holsboer-Trachsler E. High exercise levels are related to favorable sleep patterns and psychological functioning in adolescents: a comparison of athletes and controls. J Adolesc Health. 2010;46(2):133-141.

121. Kauderer S, Randler C. Differences in time use among chronotypes in adolescents. Biol Rhythm Res. 2013;44(4):601-608.

122. Schaal S, Peter M, Randler C. Morningness-eveningness and physical activity in adolescents. Int J Sport Exerc Psychol. 2010;8(2): 147-159.

123. Olds TS, Maher CA, Matricciani L. Sleep duration or bedtime? Exploring the relationship between sleep habits and weight status and activity patterns. Sleep. 2011;34(10):1299-1307.

124. Shechter A, St-Onge MP. Delayed sleep timing is associated with low levels of free-living physical activity in normal sleeping adults. Sleep Med Rev. 2014;15(12):1586-1589.

125. Kunorozva L, Stephenson KJ, Rae DE, Roden LC. Chronotype and PERIOD3 variable number tandem repeat polymorphism in individual sports athletes. Chronobiol Int. 2012;29(8):1004-1010.
126. Wheaton AG, Perry GS, Chapman DP, Croft JB. Self-reported sleep duration and weight-control strategies among US high school students. Sleep. 2013;36(8):1139-1145.

127. Cappuccio FP, Taggart FM, Kandala N-B, et al. Meta-analysis of short sleep duration and obesity in children and adults. Sleep. 2008;31(5):619-626.

128. Beebe DW, Simon S, Summer S, Hemmer S, Strotman D, Dolan LM. Dietary intake following experimentally restricted sleep in adolescents. Sleep. 2013;36(6):827-834.

129. Wing YK, Hui SH, Pak WM, et al. A controlled study of sleep related disordered breathing in obese children. Arch Dis Child. 2003;88.

130. Carotenuto M, Bruni O, Santoro N, Del Giudice EM, Perrone L, Pascotto A. Waist circumference predicts the occurrence of sleep-disordered breathing in obese children and adolescents: a questionnaire-based study. Sleep Med Rev. 2006;7(4):357-361.

131. Narang I, Mathew JL. Childhood obesity and obstructive sleep apnea. J Nutr Metab. 2012;2012:134202.

132. Golley RK, Maher CA, Matricciani L, Olds TS. Sleep duration or bedtime? Exploring the association between sleep timing behaviour, diet and BMI in children and adolescents. Int $J$ Obes. 2013;37(4):546-551.

133. Fleig D, Randler C. Association between chronotype and diet in adolescents based on food logs. Eat Behav. 2009;10(2):115-118.

134. Culnan E, Kloss JD, Grandner M. A prospective study of weight gain associated with chronotype among college freshmen. Chronobiol Int. 2013;30(5):682-690.

135. Baron KG, Reid KJ, Kern AS, Zee PC. Role of sleep timing in caloric intake and BMI. Obesity. 2011;19(7):1374-1381.

136. Kovac J, Husse J, Oster H. A time to fast, a time to feast: the crosstalk between metabolism and the circadian clock. Mol Cells. 2009;28(2):75-80

137. Thorpy MJ, Korman E, Speilman AJ, Glovinsky PB. Delayed sleep phase syndrome in adolescents. J Adolesc Health Care. 1988;9: $22-27$.

138. Crowley SJ, Acebo C, Carskadon MA. Sleep, circadian rhythms, and delayed phase in adolescence. Sleep Med Rev. 2007;8(6):602-612.

139. Uchiyama M, Okawa M, Shibui K, et al. Altered phase relation between sleep timing and core body temperature rhythm in delayed sleep phase syndrome and non-24-hour sleep-wake syndrome in humans. Neurosci Lett. 2000;294:101-104.

140. Ozaki S, Uchiyama M, Shirakawa S, Okawa M. Prolonged interval from body temperature nadir to sleep offset in patients with delayed sleep phase syndrome. Sleep. 1996;19(1):36-40.

141. Saxvig IW, Wilhelmsen-Langeland A, Pallesen S, et al. Objective measures of sleep and dim light melatonin onset in adolescents and young adults with delayed sleep phase disorder compared to healthy controls. J Sleep Res. 2013;22(4):365-372.

142. Shibui K, Uchiyama M, Okawa M. Melatonin rhythms in delayed sleep phase syndrome. J Biol Rhythms. 1999;14(1):72-76.

143. Chang AM, Reid KJ, Gourineni R, Zee PC. Sleep timing and circadian phase in delayed sleep phase syndrome. J Biol Rhythms. 2009;24(4):313-321.

144. Oren DA, Turner EH, Wehr TA. Abnormal circadian rhythms of plasma melatonin and body temperature in the delayed sleep phase syndrome. J Neurol Neurosurg Psychiatry. 1995;58:379-385.

145. Kamei Y, Hayakawa T, Urata J, et al. A randomized, double-blind, placebo-controlled crossover study of the effect of exogenous melatonin on delayed sleep phase syndrome. Psychiatry Clin Neurosci. 2000;54:381-382.

146. Nagtegaal JE, Kerkhof GA, Smits MG, Swart ACW, Van Der Meer YG. Delayed sleep phase syndrome: a placebo-controlled cross-over study on the effects of melatonin administered five hours before the individual dim light melatonin onset. J Sleep Res. 1998;7:135-143.

147. Kayumov L, Brown G, Jindal R, Buttoo K, Shapiro CM. A randomized, double-blind, placebo-controlled crossover study of the effect of exogenous melatonin on delayed sleep phase syndrome. Psychosom Med. 2001;63:40-48 
148. Sivertsen B, Harvey AG, Lundervold AJ, Hysing M. Sleep problems and depression in adolescence: results from a large population-based study of Norwegian adolescents aged 16-18 years. Eur Child Adolesc Psychiatry. 2014;23(8):681-689.

149. Regestein QR, Monk TH. Delayed sleep phase syndrome: a review of its clinical aspects. Am J Psychiatry. 1995;152(4):602-608.

150. Benca RM, Obermeyer WH, Thisted RA, Gillin CJ. Sleep and psychiatric disorders: a meta-analysis. Arch Gen Psychiatry. 1992;49: 651-668.

151. Chouinard S, Poulin J, Stip E, Qodbout R. Sleep in untreated patients with schizophrenia: a meta-analysis. Schizophr Bull. 2004;30(4): 957-967.

152. Pillai V, Kalmbach DA, Ciesla JA. A meta-analysis of electroencephalographic sleep in depression: evidence for genetic biomarkers. Biol Psychiatry. 2011;70(10):912-919.

153. Cortese S, Faraone SV, Konofal E, Lecendreux M. Sleep in children with attention-deficit/hyperactivity disorder: meta-analysis of subjective and objective studies. JAm Acad Child Adolesc Psychiatry. 2009; 48(9):894-908.

154. Glozier N, O'Dea B, McGorry PD, et al. Delayed sleep onset in depressed young people. BMC Psychiatry. 2014;14:33.

155. Robillard R, Naismith SL, Rogers NL, et al. Delayed sleep phase in young people with unipolar or bipolar affective disorders. $J$ Affect Disord. 2013;145(2):260-263.

156. Turner J, Drummond LM, Mukhopadhyay S, et al. A prospective study of delayed sleep phase syndrome in patients with severe resistant obsessive-compulsive disorder. World Psychiatry. 2007;6: 108-111.

157. Teicher MH, Glod CA, Magnus E, et al. Circadian rest-activity disturbances in seasonal affective disorder. Arch Gen Psychiatry. 1997;54:124-130.

158. Robillard R, Hermens DF, Naismith SL, et al. Ambulatory sleepwake patterns and variability in young people with emerging mental disorders. J Psychiatry Neurosci. 2015;40(1):28-37.

159. van der Heijden KB, Smits MG, Gunning WB. Sleep-related disorders in ADHD: a review. Clin Pediatr (Phila). 2005;44:201-210.

160. Imeraj L, Sonuga-Barke E, Antrop I, et al. Altered circadian profiles in attention-deficit/hyperactivity disorder: an integrative review and theoretical framework for future studies. Neurosci Biobehav Rev. 2012;36(8):1897-1919.

161. Papadimitriou GN, Linkowski P. Sleep disturbance in anxiety disorders. Int Rev Psychiatry. 2005;17(4):229-236.

162. van Mill JG, Hoogendijk WJ, Vogelzangs N, van Dyck R, Penninx BW. Insomnia and sleep duration in a large cohort of patients with major depressive disorder and anxiety disorders. J Clin Psychiatry. 2010; 71(3):239-246.

163. Chase RM, Pincus DB. Sleep-related problems in children and adolescents with anxiety disorders. Behav Sleep Med. 2011;9(4): 224-236.

164. Breslau N, Roth T, Rosenthal L, Andreski P. Sleep disturbance and psychiatric disorders: a longitudinal epidemiological study of young adults. Biol Psychiatry. 1996;39:411-418.

165. Harvey AG, Talbot LS, Gershon A. Sleep disturbance in bipolar disorder across the lifespan. Clin Psychol. 2009;16(2):256-277.

166. Wulff K, Dijk DJ, Middleton B, Foster RG, Joyce EM. Sleep and circadian rhythm disruption in schizophrenia. Br J Psychiatry. 2012;200(4):308-316.

167. Brower KJ, Aldrich MS, Hall JM. Sleep-disordered breathing in alcoholics. Alcohol Clin Exp Res. 1999;23(1).

168. Roehrs T, Roth T. Sleep, sleepiness, sleep disorders and alcohol use and abuse. Sleep Med Rev. 2001;5(4):287-297.

169. Chellappa SL, Araújo JF. Excessive daytime sleepiness in patients with depressive disorder. Rev Bras Psiquiatr. 2006;28(2):126-129.

170. Breslau N, Roth T, Rosenthal L, Andreski P. Daytime sleepiness: an epidemiological study of young adults. Am J Public Health. 1997;87: 1649-1653.
171. Kessler RC, Berglund P, Demler O, Jin R, Merikangas KR, Walters EE. Lifetime prevalence and age-of-onset distributions of DSM-IV disorders in the national comorbidity survey replication. Arch Gen Psychiatry. 2005;62:593-602.

172. Kessler RC, Angermeyer M, Anthony JC, et al. Lifetime prevalence and age-of-onset distributions of mental disorders in the World Health Organization's World Mental Health Survey Initiative. World Psychiatry. 2007;6:168-176.

173. Harris M, Glozier N, Ratnavadivel R, Grunstein RR. Obstructive sleep apnea and depression. Sleep Med Rev. 2009;13(6):437-444.

174. Yilmaz E, Sedky K, Bennett DS. The relationship between depressive symptoms and obstructive sleep apnea in pediatric populations: a meta-analysis. J Clin Sleep Med. 2013;9(11):1213-1220.

175. Peppard PE, Szklo-Coxe M, Hla KM, Young T. Longitudinal association of sleep-related breathing disorder and depression. Arch Intern Med. 2006;166:1709-1715.

176. Ankers D, Jones SH. Objective assessment of circadian activity and sleep patterns in individuals at behavioural risk of hypomania. J Clin Psychol. 2009;65(10):1071-1086.

177. Jackson A, Cavanagh J, Scott J. A systematic review of manic and depressive prodromes. J Affect Disord. 2003;74(3):209-217.

178. Yung AR, McGorry PD. The initial prodrome in psychosis: descriptive and qualitative aspects. Aust NZJ Psychiatry. 1996;30: 587-599.

179. Naismith SL, Hermens DF, Ip TK, et al. Circadian profiles in young people during the early stages of affective disorder. Transl Psychiatry. 2012;2:e123.

180. Scott EM, Robillard R, Hermens DF, et al. Dysregulated sleep-wake cycles in young people are associated with emerging stages of major mental disorders. Early Interv Psychiatry. 2014.

181. Glod CA, Teicher MH, Polcari A, McGreenery CE, Ito Y. Circadian rest-activity disturbances in children with seasonal affective disorder. J Am Acad Child Adolesc Psychiatry. 1997;36(2):188-195.

182. Teicher MH, Glod CA, Harper D, et al. Locomotor activity in depressed children and adolescents: I. Circadian dysregulation. JAm Acad Child Adolesc Psychiatry. 1993;32(4):760-769.

183. Jones SH, Hare DJ, Evershed K. Actigraphic assessment of circadian activity and sleep patterns in bipolar disorder. Bipolar Disord. 2005;7:176-186.

184. Gruber R, Sadeh A, Raviv A. Instability of sleep patterns in children with attention-deficit/hyperactivity disorder. JAm Acad Child Adolesc Psychiatry. 2000;39(4):495-501.

185. Biggs SN, Lushington K, van den Heuvel CJ, Martin AJ, Kennedy JD. Inconsistent sleep schedules and daytime behavioral difficulties in school-aged children. Sleep Med Rev. 2011;12(8):780-786.

186. Ong SH, Wickramaratne P, Tang M, Weissman MM. Early childhood sleep and eating problems as predictors of adolescent and adult mood and anxiety disorders. $J$ Affect Disord. 2006;96(1-2): $1-8$.

187. Murray G. Diurnal mood variation in depression: a signal of disturbed circadian function? J Affect Disord. 2007;102(1-3):47-53.

188. Peeters F, Berkhof J, Delespaul P, Rottenberg J, Nicolson NA. Diurnal mood variation in major depressive disorder. Emotion. 2006;6(3):383-391.

189. Wirz-Justice A. Diurnal variation of depressive symptoms. Dialogues Clin Neurosci. 2008;10(3):337-343.

190. Schiefelbein VL, Susman EJ. Cortisol levels and longitudinal cortisol change as predictors of anxiety in adolescents. $J$ Early Adolesc. 2006;26(4):397-413.

191. Walker EF, Walder DJ, Reynolds F. Developmental changes in cortisol secretion in normal and at-risk youth. Dev Psychopathol. 2001;13:721-732.

192. Adam EK, Doane LD, Zinbarg RE, Mineka S, Craske MG, Griffith JW. Prospective prediction of major depressive disorder from cortisol awakening responses in adolescence. Psychoneuroendocrinology. 2010;35(6):921-931. 
193. Goodyer IM, Herbert J, Altham PM, Pearson J, Secher SM, Shiers HM. Adrenal secretion during major depression in 8- to 16-year-olds, I. Altered diurnal rhythms in salivary cortisol and dehydroepiandrosterone (DHEA) at presentation. Psychol Med. 1996;26:245-256.

194. Dahl RE, Ryan ND, Puig-Antich J, et al. 24-Hour cortisol measures in adolescents with major depression: a controlled study. Biol Psychiatry. 1991;30:25-36.

195. Cervantes P, Gelber S, Kin FN, Nair VNP, Schwartz G. Circadian secretion of cortisol in bipolar disorder. $J$ Psychiatry Neurosci. 2001;26(5):411-416.

196. Nair NVP, Hariharasubraman N, Pilapil C. Circadian rhythm of plasma melatonin in endogenous depression. Prog Neuropsychopharmacol Biol Psychiatry. 1984;8:715-718.

197. Claustrat B, Chazot G, Bran J, Jordan D, Sassolas G. A chronobiological study of melatonin and cortisol secretion in depressed subjects: plasma melatonin, a biochemical marker in major depression. Biol Psychiatry. 1984;19(8):1215-1228.

198. Kennedy SH, Kutcher SP, Ralevski E, Brown GM. Nocturnal melatonin and 24-hour 6-sulphatoxymelatonin levels in various phases of bipolar affective disorder. Psychiatry Res. 1996;63:219-222.

199. Robillard R, Naismith SL, Rogers NL, et al. Sleep-wake cycle and melatonin rhythms in adolescents and young adults with mood disorders: comparison of unipolar and bipolar phenotypes. Eur Psychiatry. 2013;28(7):412-416.

200. Monteleone P, Catapano F, Del Buono G, Maj M. Circadian rhythms of melatonin, cortisol and prolactin in patients with obsessive-compulsive disorder. Acta Psychiatr Scand. 1994;89:411-415.

201. Robinson S, Rosca P, Durst R, et al. Serum melatonin levels in schizophrenic and schizoaffective hospitalized patients. Acta Psychiatr Scand. 1991;84:221-224.

202. Monteleone P, Maj M, Fusco M, Kemali D, Reiter RJ. Depressed nocturnal plasma melatonin levels in drug-free paranoid schizophrenics. Schizophr Res. 1992;7:77-84.

203. Rao ML, Gross G, Strebel B, et al. Circadian rhythm of tryptophan, serotonin, melatonin, and pituitary hormones in schizophrenia. Biol Psychiatry. 1994;35:151-163.

204. Singh SP, Singh V, Kar N. Efficacy of agomelatine in major depressive disorder: meta-analysis and appraisal. Int J Neuropsychopharmacol. 2012;15(3):417-428.
205. Hickie IB, Naismith SL, Robillard R, Scott EM, Hermens DF. Manipulating the sleep-wake cycle and circadian rhythms to improve clinical management of major depression. BMC Med. 2013;11:79.

206. Hickie IB, Rogers NL. Novel melatonin-based therapies: potential advances in the treatment of major depression. Lancet. 2011; 378(9791):621-631.

207. Xu X, Breen G, Chen CK, Huang YS, Wu YY, Asherson P. Association study between a polymorphism at the $3^{\prime}$-untranslated region of CLOCK gene and attention deficit hyperactivity disorder. Behav Brain Funct. 2010;6:48.

208. Kishi T, Fukuo Y, Kitajima T, et al. SIRT1 gene, schizophrenia and bipolar disorder in the Japanese population: an association study. Genes Brain Behav. 2011;10(3):257-263.

209. Huang MC, Ho CW, Chen CH, Liu SC, Chen CC, Leu SJ. Reduced expression of circadian clock genes in male alcoholic patients. Alcohol Clin Exp Res. 2010;34(11):1899-1904.

210. McCarthy MJ, Nievergelt CM, Kelsoe JR, Welsh DK. A survey of genomic studies supports association of circadian clock genes with bipolar disorder spectrum illnesses and lithium response. PLoS One. 2012;7(2):e32091.

211. Kripke DF, Nievergelt CM, Joo E, Shekhtman T, Kelsoe JR. Circadian polymorphisms associated with affective disorders. $J$ Circadian Rhythms. 2009;7:2.

212. Soria V, Martinez-Amoros E, Escaramis G, et al. Differential association of circadian genes with mood disorders: CRY1 and NPAS2 are associated with unipolar major depression and CLOCK and VIP with bipolar disorder. Neuropsychopharmacology. 2010;35(6): 1279-1289.

213. Mansour HA, Wood J, Logue T, et al. Association study of eight circadian genes with bipolar I disorder, schizoaffective disorder and schizophrenia. Genes Brain Behav. 2006;5(2):150-157.

214. McGrath CL, Glatt SJ, Sklar P, et al. Evidence for genetic association of RORB with bipolar disorder. BMC Psychiatry. 2009;9:70.

215. Park HJ, Park JK, Kim SK, et al. Association of polymorphism in the promoter of the melatonin receptor $1 \mathrm{~A}$ gene with schizophrenia and with insomnia symptoms in schizophrenia patients. $J$ Mol Neurosci. 2011;45(2):304-308.

216. Mongrain V, Cermakian N. Clock genes in health and diseases. J Appl Biomed. 2009;7:15-33.
ChronoPhysiology and Therapy

\section{Publish your work in this journal}

ChronoPhysiology and Therapy is an international, peer-reviewed, open access journal focusing on research into the cyclic variations and rhythmicity in physiological processes in the body and the research and development and optimal timing of administration of therapeutic targets to achieve improved outcomes and quality of life for the patient. The

\section{Dovepress}

manuscript management system is completely online and includes a very quick and fair peer-review system. Visit http://www.dovepress.com/ testimonials.php to read real quotes from published authors. 